\title{
China braucht mehr Controlling!
}

\section{Erste chinesisch-deutsche Controlling-Konferenz in Shanghai}

Noch ist die Finanzfunktion chinesischer Unternehmen in hohem Maße von Fragen des Rechnungswesens und der internen Revision geprägt. Das Controlling-Verständnis westlicher Unternehmen und auch die dafür erforderliche Transparenzkultur sind allenfalls in Ansätzen vorhanden. Doch beginnen erste Unternehmen und auch die chinesische Wissenschaft, sich mit dem Thema zu beschäftigen. Zudem betont die politische Führung im Ministry of Finance neuerdings die Bedeutung von „Management Accounting". Vor diesem Hintergrund kamen bei der ersten chinesisch-deutschen Controller-Konferenz am 26. Oktober 2013 in Shanghai mehr als 250 chinesische Finanzvorstände und Führungskräfte in der Finanzfunktion sowie interessierte deutsche Praktiker zusammen. Sie trafen sich auf dem Campus des Shanghai National Accounting Institutes (SNAI), um das Konzept des Controllings kennenzulernen und mit Blick auf seine Anwendbarkeit in einem chinesischen Kontext zu diskutieren.

Die von SNAI und dem Internationalen Controller Verein veranstaltete und von Skoda sowie Volkswagen Shanghai unterstützte Konferenz wurde von Professor Kouquing Li, Präsident von SNAI, und durch ein auf Video übertragenes Grußwort von Siegfried Gänßlen, Vorsitzender des Internationalen Controller Vereins, eröffnet. Professor Utz Schäffer stellte das Konzept des Controllings sowie das Grundlagenpapier von Internationalem Controller Verein und der International Group of Controlling vor. Seine Kernthese: Controller sind in Deutschland deshalb so erfolgreich, weil sie einen wesentlichen Beitrag zum wirtschaftlichen Erfolg des Unternehmens leisten. Als Partner des Managements verbinden sie die Welt der Zahlen zukunftsorientiert mit dem operativen Geschäft. Ein flammendes Plädoyer für mehr Controlling in chinesischen Unternehmen hielt auch Bernd Pichler von Shanghai Volkswagen Automotive und stellte die Praxis des Vertriebs-Controllings bei Volkswagen in China vor. Dr. Zhen Huang, Corporate Performance Architects, rief die Teilneh-

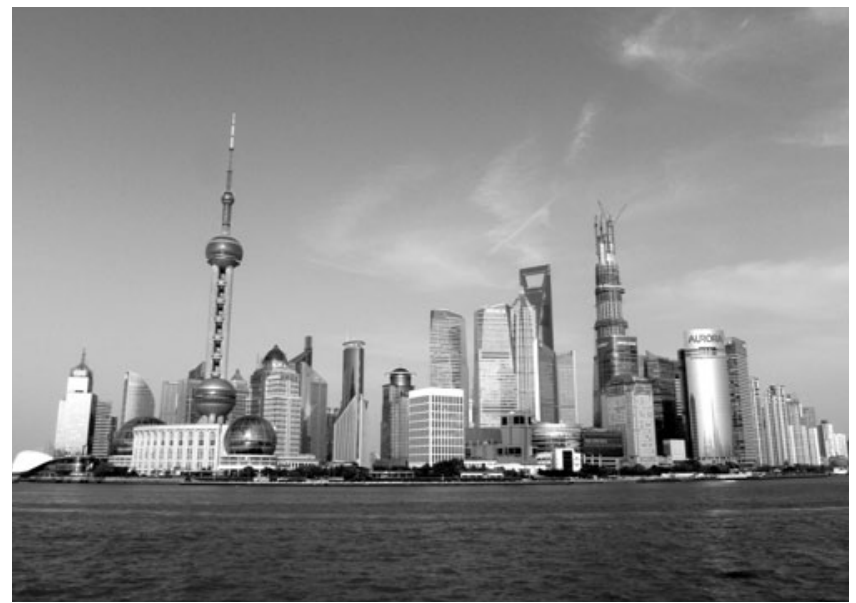

mer dazu auf, Controlling in China als „People Business“ zu sehen. Über das Controlling-Verständnis und die Controlling-Praxis aus chinesischer Sicht sprachen Professor Jiang Bailing, SNAI, und Renalda Liu, Lucanet. Dass es einzelne Pioniere gibt, die auch in China bereits konsequent den Weg in Richtung mehr Controlling gehen, wurde im Vortrag von Janiung Liu, CFO von Bao Steel, deutlich. Sein Unternehmen hatte im Controlling eine Antwort auf eine Unternehmenskrise in 2009 gefunden.

Die Teilnehmer waren sich einig: Controlling wird im Zuge einer fortschreitenden Globalisierung und vor dem Hintergrund einer möglichen Abschwächung des Wachstums in China zunehmend erforderlich werden. Die damit verbundene Herausforderung ist gewaltig. Institutionelle Faktoren und tief verwurzelte kulturelle Aspekte wie eine dominierende Management-Philosophie, die weder interner Transparenz noch interner Kritik einen hohen Stellenwert beimisst, machen die Übertragung des Konzepts zur Herausforderung. Entsprechend bekundeten alle Teilnehmer großes Interesse an einer Fortsetzung des Dialogs durch eine zweite chinesisch-deutsche Controlling-Konferenz in 2014.

Prof. Dr. Utz Schäffer, Vallendar 